\title{
319 周期的加熱を受ける不均質片持ちはりの熱誘起振動問題 Themally Induced Vibration Problem of an Inhomogeneous Cantilever Beam Subjected to Cyclic Heat Supply
}

\author{
○学 三國 敦 （阪府大院） 正 河村 隆介（阪府大院） \\ 正 谷川 義信（阪府大院）
}

Mikuni Atsushi, Ryusuke Kawamura and Yoshinobu Tanigawa

Graduate School of Engineering, Osaka Prefecture University

Gakuen-cho 1-1, Sakai, Osaka 599-8531

\begin{abstract}
This study is concerned with theoretical development for thermally induced vibration problem of an inhomogeneous beam. We suppose that thermal and mechanical material properties in beam are given as power function in term of transverse coordinate $z$. Firstly, we have developed one-dimensional transient heat conduction problem of an inhomogeneous beam due to cyclic heat supply. Then, we have developed thermally induced vibration problem of an inhomogeneous beam clamped at one edge and free at opposite edge. Next, we have carried out numerical calculations and have discussed about effects of both cyclic temperature fluctuation and nonhomogeneity of material properties on thermal displacements, thermal stresses and resonance characteristics.
\end{abstract}

Key Words : Thermoelasticity, Thermally induced vibration, Inhomogeneous material, Cantilever beam

\section{1 はじめに}

近年、材料分野での複合材料や傾斜機能材料などの新 秦材開発は, 棬造部材の眭量化, 高強度化に奇与してい る.このような怪量化によって部材の肉厚が大幅に減少 するため, 特に, 外力と温度の周期的な変動を伴う渨境 下で使用される場合，共振や疲労による破損を予測する 上で動的応答解析が重要視されている。 しかし，外力と 温度の周期的な変動を受ける不均質材料からなる薄肉構 造物に対する動的熱弹性応答問題を解析的に取り扱った 研究は見られない。

そこで本研究では，解析モデルとして物性值が高さ方 向の座標変数に関するべき乗関数の形で与えられる不均 質弾性体からなるはりを取り上げる。 そして，このはり の表面に周期的な温度変動を与えた場合の熱誘起振動問 題を，一端固定他端自由の条件の下で理論解析を行なう. さらに，周期的な温度変動および材料物性の不均質性が はりの熱応力, 熱変形, 共振特性に及ほす影鄧を数值計 算により明らかにする。

\section{2 解析}

\section{1 熟伝噴解析}

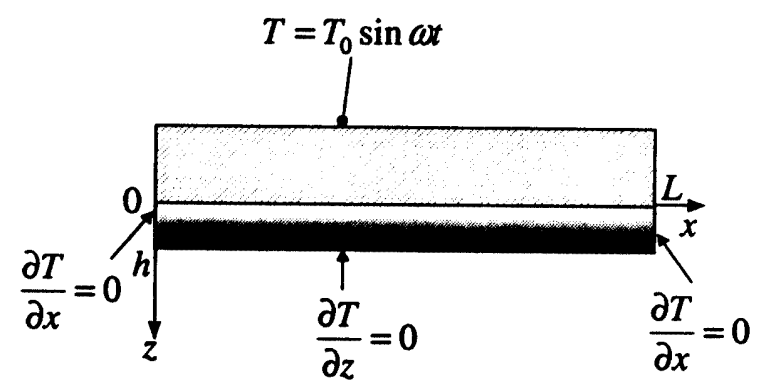

Fig.1 Analytical model and conditions
Fig.1 のような幅 $b$, 高さ $h$, 長さ $L$ の長方形断面の不 均質はりを取り上げる. 時刻 $t=0$ の瞬間から上面が周 期的な温度変動を受けている場合を想定する。.またはり の下面および両端面は断熱状態に保たれていると仮定す る.この時, はりの非定常熱伝道の基碳方程式, 初期条 件および境界条件は以下のようになる。

$$
\begin{aligned}
& c(z) \rho(z) \frac{\partial T}{\partial t}=\frac{\partial}{\partial z}\left\{\lambda(z) \frac{\partial T}{\partial z}\right\} \\
& t=0 ; T=0 \\
& z=0 ; T=T_{0} \sin \omega t \\
& z=h ; \quad \frac{\partial T}{\partial z}=0
\end{aligned}
$$

ここで, $\lambda(z), c(z) \rho(z)$ は熱伝導束およひ熱容量であり， $z$ 方向に関して次式のような不均啠特性を持つ場合を考 える.

$$
\lambda(z)=\lambda_{0}\left(1+\frac{z}{h}\right)^{l}, c(z) \rho(z)=c_{0} \rho_{0}\left(1+\frac{z}{h}\right)^{k}
$$

ただし， $k, l$ は不均質性を表す数值パラメータである.

式 (5) を式 (1) に代入し，式 (2) 式 (4) のもとで解く と, 温度解 $T(z, t)$ は複素変数第 1 種, 第 2 種実数 Bessel 関数を用いて表される.ここで，

$$
k=-l \quad(-1<k, l<1)
$$

の関保が成り立つとき, 温度解は初等関数により表される.

$$
\begin{aligned}
\bar{T}(\zeta, \tau)=- & \sum_{j=1}^{\infty} \frac{2(-1)^{j} \bar{\omega} q_{j} e^{-q_{j}{ }^{2} \tau} \cos \left\{p_{3}\left(\zeta^{p_{2}}-2^{p_{2}}\right) q_{j}\right\}}{\left(q_{j}{ }^{4}+\bar{\omega}^{2}\right) p_{3}\left(2^{p_{2}}-1\right)} \\
+ & \frac{1}{\cos ^{2} \beta \cosh ^{2} \beta+\sin ^{2} \beta \sinh ^{2} \beta} \\
& \times[\{\sin \alpha \sinh \alpha \cos \beta \cosh \beta \\
& -\cos \alpha \cosh \alpha \sin \beta \sinh \beta\} \cos \bar{\omega} \tau \\
& +\{\cos \alpha \cosh \alpha \cos \beta \cosh \beta \\
& +\sin \alpha \sinh \alpha \sin \beta \sinh \beta\} \sin \bar{\omega} \tau] \quad \text { (7) }
\end{aligned}
$$


ただし，

$$
\begin{aligned}
& p_{2}=1-l, p_{3}=1 /\left|p_{2}\right| \\
& \alpha \equiv p_{3}\left(\frac{\bar{\omega}}{2}\right)^{\frac{1}{2}}\left(\zeta^{p_{2}}-2^{p_{2}}\right), \beta \equiv p_{3}\left(\frac{\bar{\omega}}{2}\right)^{\frac{1}{2}}\left(1-2^{p_{2}}\right)
\end{aligned}
$$

また，式 (7) で導入された無次元量は次式で定義される.

$$
\left.\begin{array}{l}
\bar{T}=\frac{T}{T_{0}}, \zeta=1+\frac{z}{h}, \kappa_{0}=\frac{\lambda_{0}}{c_{0} \rho_{0}}, \\
\tau=\frac{\kappa_{0} t}{h^{2}}, \bar{\omega}=\frac{\omega h^{2}}{\kappa_{0}}
\end{array}\right\}
$$

\section{2 熱弾性解析}

縋弾性係数 $E$, 線獥張係数 $\alpha$ が $z$ 方向に関して次式の ような不均質特性を持つ場合のはりを考える。

$$
E(z)=E_{0}\left(1+\frac{z}{h}\right)^{m} \quad, \quad \alpha(z)=\alpha_{0}\left(1+\frac{z}{h}\right)^{n}
$$

ここで, はりの微小要素における $z, x$ 方向の力のつり合 い, 要素左端周りのモーメントのつり合いを考え, はり のたわみを $w$, 中立面での面内変位を $u_{0}$ とすると， $x, z$ 方向の慣性力の影㨨を無視した場合のはりの面外及び面 内方向に関する運動方程式は

$$
\begin{gathered}
c_{2} \frac{\partial^{4} w}{\partial x^{4}}+\mu \frac{\partial^{2} w}{\partial t^{2}}+\frac{\partial^{2} M_{T}}{\partial x^{2}}=0 \\
c_{1} \frac{\partial^{2} u_{0}}{\partial x^{2}}-\frac{\partial N_{T}}{\partial x}-\mu \frac{\partial^{2} u_{0}}{\partial t^{2}}+\delta \frac{\partial^{2}}{\partial t^{2}}\left(\frac{\partial w}{\partial x}\right)=0
\end{gathered}
$$

となる ${ }^{1)}$ 。ただし， $\mu$ ははりの単位長さあたりの質量， $M_{T}, N_{T}$ はそれぞれ熱曲げモーメント，熱面内力を表す。

ここで，面外方向に関するはりの中立面の位置を $\eta$ と 表し, 以下の無次元量

$$
\begin{aligned}
\bar{c}_{1} & =\int_{1}^{2} \zeta^{m} d \zeta, \bar{c}_{2}=\int_{1}^{2} \zeta^{m}(\zeta-1-\bar{\eta})^{2} d \zeta \\
\bar{\eta} & =\int_{1}^{2} \zeta^{m}(\zeta-1) d \zeta / \int_{1}^{2} \zeta^{m} d \zeta \\
\bar{M}_{T} & =\int_{1}^{2} \zeta^{m+n}(\zeta-1-\bar{\eta}) \bar{T}(\zeta, \tau) d \zeta \\
\bar{N}_{T} & =\int_{1}^{2} \zeta^{m+n} \bar{T}(\zeta, \tau) d \zeta
\end{aligned}
$$

を導入する，そして，一端固定他端自由の支持条件

$$
\left.\begin{array}{ll}
\bar{x}=0 & : \quad \bar{w}=0, \quad \frac{\partial \bar{w}}{\partial \bar{x}}=0 \\
\bar{x}=1 & : \quad \frac{\partial^{2} \bar{w}}{\partial \bar{x}^{2}}=0, \quad \frac{\partial^{3} \bar{w}}{\partial \bar{x}^{3}}=0
\end{array}\right\}
$$

のもとで，運動方程式を解くと，たわみの慣性力を無視 した準静的解 $w$ は式 (19), 慣性項を考慮した動的解 $w$ は (21) で表される.

$$
\bar{w}=-\frac{\bar{M}_{T}}{2 \bar{c}_{2} \bar{h}^{2}} \bar{x}^{2}
$$

$$
\begin{aligned}
\bar{w}= & \sum_{i=1}^{\infty} \frac{\left\{\cosh \bar{\phi}_{i} \bar{x}-\cos \bar{\phi}_{i} \bar{x}-\Delta_{i}\left(\sinh \bar{\phi}_{i} \bar{x}-\sin \bar{\phi}_{i} \bar{x}\right)\right\}}{\bar{c}_{2} \bar{h}^{2} \bar{\phi}_{i}^{4}} \\
\times & \sum_{m=1}^{\infty} \alpha_{m}^{2} F_{m}\left(\bar{\phi}_{i}\right) \\
& \times\left\{\sum_{j=1}^{\infty} \frac{C_{1 m j}}{1+q_{j}{ }^{4} / \Omega_{i}^{2}}\left(\cos \Omega_{i} \tau-\frac{q_{j}^{2}}{\Omega_{i}} \sin \Omega_{i} \tau\right)\right. \\
& -\frac{1}{1-\bar{\omega}^{2} / \Omega_{i}^{2}}\left(C_{2 m} \cos \Omega_{i} \tau+\frac{\bar{\omega} C_{3 m}}{\Omega_{i}} \sin \Omega_{i} \tau\right) \\
& -\sum_{j=1}^{\infty} \frac{C_{1 m j}}{1+q_{j}{ }^{4} / \Omega_{i}^{2}} e^{-q_{j}{ }^{2} \tau} \\
& \left.+\frac{1}{1-\bar{\omega}^{2} / \Omega_{i}^{2}}\left(C_{2 m} \cos \bar{\omega} \tau+C_{3 m} \sin \bar{\omega} \tau\right)\right\}
\end{aligned}
$$

\section{3 数值計算結果}

2 章で得られた解析結果について数值計算を実行した. 数值計算結果の一例として，たわみの準静的解の時間変 化のグラフをのせる. また数値計算諸元を以下のように 与えた.

$$
\left.\begin{array}{l}
L=3.02[m], h=5 \times 10^{-3}[m] \\
k=l=m=n=0 \\
\bar{\omega}=\varepsilon \Omega_{1}, \varepsilon=0.9
\end{array}\right\}
$$

ただし、 $\Omega_{1}$ は均質はりの曲げ振動に関する基本固有振動 数である.

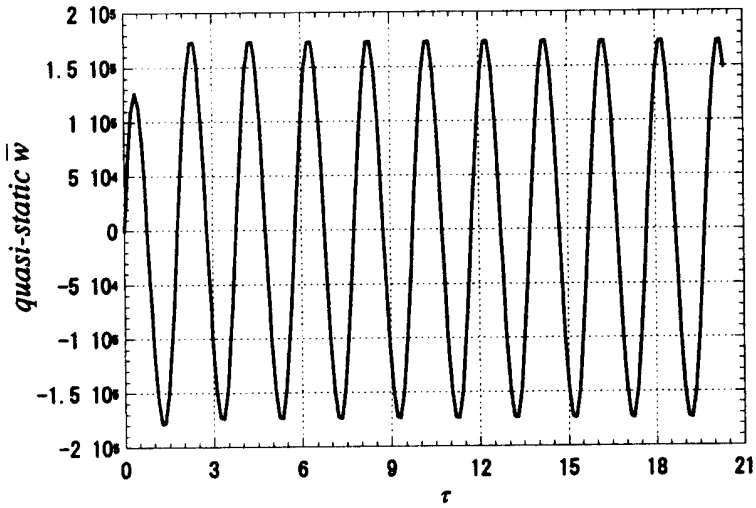

Fig.2 Time-evolution of deflection

\section{4 おわりに}

本稿では, 熱伝導率, 熱容量, 縦弾性係数および線膨 張係数の不均質特性が高さ方向の座標変数に関するべき 乗関数で与えられる不均質はりを対象として，一次元非 定常温度变化とたわみのの準静的解と動的解を導出した. 面内変位および熱応力の準静的解, 動的解については, 講 演会当日に詳細を発表する。

\section{参考文献}

（1）系川 潤, 周期的加熱を受ける不均質はりの動的応 答問題, 平成 13 年度大阪府立大学大学院工学研究科 修士論文, 2002. 